\title{
Effects of Rapid Water-Level Fluctuations on the Stability of an Unsaturated Reservoir Bank Slope
}

\author{
Jin-Zhu Mao, ${ }^{1}$ Jia Guo, ${ }^{2}$ Yong Fu $\mathbb{D}^{3},{ }^{3}$ Wei-Peng Zhang, ${ }^{1}$ and Ya-Nan Ding ${ }^{4}$ \\ ${ }^{1}$ Changjiang Survey, Planning, Design and Research Co., Ltd. (CSPDR), Changjiang, Hubei 430015, China \\ ${ }^{2}$ Department of Civil Engineering and Mechanics, Faculty of Engineering, China University of Geosciences, Wuhan, \\ Hubei 430074, China \\ ${ }^{3}$ Department of Ocean Science and Engineering, Southern University of Science and Technology, Shenzhen 518055, China \\ ${ }^{4}$ State Key Laboratory of Water Resources and Hydropower Engineering Science, \\ Institute of Engineering Risk and Disaster Prevention, Wuhan University, 299 Bayi Road, Wuhan 430072, China
}

Correspondence should be addressed to Yong Fu; fuyong@u.nus.edu

Received 27 July 2019; Revised 26 December 2019; Accepted 3 February 2020; Published 28 April 2020

Academic Editor: Khalid Abdel-Rahman

Copyright (C) 2020 Jin-Zhu Mao et al. This is an open access article distributed under the Creative Commons Attribution License, which permits unrestricted use, distribution, and reproduction in any medium, provided the original work is properly cited.

The instability of reservoir slope is likely to cause some severe natural hazards such as surge and barrier lake. In this study, the changes in seepage field and the distribution of the unsaturated zone of a reservoir bank slope subjected to rapid water-level fluctuations are investigated using the finite element method. The stability analysis of a reservoir slope under water-level fluctuation with a rate of $2 \mathrm{~m} /$ day is performed. The stability analysis is based on the theory of unsaturated soil mechanics and saturated-unsaturated seepage and accounts for the hydromechanical coupling effect. The changes in shear stress and strain as well as pore water pressure due to rapid water-level fluctuations are explicitly examined. Furthermore, the stability factor of safety, the underlying failure mechanism, and relevant influence factors are discussed. Based on the finite element analysis, it is found that the rapid loss of matrix suction would give rise to the surface landslide near the slope toe.

\section{Introduction}

The instability of reservoir slope is likely to cause some natural hazards such as surge and barrier lake when the reservoir water-level fluctuates rapidly (see, e.g., [1-3]). The danger derives from unsaturated residual soil due to rapid water-level fluctuations of a reservoir bank slope. A key influence factor is the matrix suction which varies according to the changes in water seepage and water infiltration line. As reported by $\mathrm{Ng}$ et al. [4], the rainfall infiltration would reduce the matrix suction, resulting in an increase in moisture content and soil permeability in unsaturated soil. The failure criterion of strength of unsaturated soil differs from that of saturated soil, which increases the difficulty of studying the stability of unsaturated soil slope [5]. Fredlund et al. [6] developed a Mohr-Coulomb shear strength theory for extensional unsaturated soil. Furthermore, Fredlund et al. [7] proposed a slope stability evaluation method (GLE method) which accounts for the matric suction.

To investigate the stability of unsaturated soil slope, the theory of limit equilibrium with respect to unsaturated soil is commonly used. For example, Qi and Vanapalli [8] reported the formulation for calculating slope safety factor based on the strength theory of unsaturated soil and the limit equilibrium method and discussed the stability of unsaturated soil slope under rainfall infiltration. Liu et al. $[9,10]$ simulated the undrained shear strength as a random field to reflect the spatial variability of slope soil properties and combined the Monte Carlo method to determine the factor of safety. Hiroyuki et al. [11] reported that the influence factors for landslide stability in reservoir areas include the immersion of the reservoir water, the sharp decline of the reservoir water-level, and the rainstorm. Fredlund and Rahardjo [12] proposed a method for calculating the critical 
height of vertical or nearly vertical slopes based on the theory of earth pressure in unsaturated soil. Fredlund et al. [13] put forth a nonlinear law for the variation of shear strength of unsaturated soil with matric suction based on the soil-water characteristic curve equation of unsaturated soil. Zhang et al. [14] and Luo and Ye [15] noticed that when the water-level fluctuates dramatically, the infiltration line and the matric suction field on the slope will change significantly and subsequently affect the stability of the bank slope. However, the slope reliability analysis as well as the changes in seepage field and the unsaturated zone of a reservoir bank slope subjected to rapid water-level fluctuations has not been discussed in these studies.

The effects of rapid water-level fluctuations on the stability of the reservoir slope in unsaturated soil still remain unclear. Unlike saturated soil, the interaction between pore air pressure and pore water pressure in unsaturated soil is more complicated. Firstly, the pore pressure in unsaturated soil may become negative, thereby reducing the effective soil stress [16]. Secondly, the water content and the permeability coefficient in unsaturated soil vary spatially which may cause soil-water content and permeability coefficient exhibiting spatial variability [17-19]. Thirdly, the failure criterion of strength of saturated soil differs from that of unsaturated soil. All these lead to the difficulty of studying the slope stability in unsaturated soil.

In this study, a genuine engineering case of reservoir landslide at Nuozhadu Reservoir area in Yunnan Province is examined using the finite element method. The hydraulic effect of water-level fluctuations on the interior of unsaturated soil slope is considered. The suction matrix is used to calculate the influence of a changing rate of water-level on the unsaturated soil of the typical landslide deposit $H_{12}$ of an engineering example of bank slope investigation in Nuozhadu Reservoir area. In the stability analysis of the slope, the coupling effects of matrix suction in the unsaturated area, pore water seepage in the saturated area, and gravity stress field of rock and soil are taken into account. The results can serve as a reference for stability evaluation of reservoir bank and river side slopes and other related engineering areas (see, e.g., Chen et al. [20]).

\section{Finite Element Model}

2.1. Model Setup. By collecting of relevant data and field geological investigation in Nuozhadu Reservoir area, it is found that $H_{12}$ is an ancient landslide accumulation body, which is located in the branch of Lancang River. Figure 1 shows the overall picture of the landslide accumulation body, with obvious landslide morphology. Figure 2 is a section sketch of $H_{12}$. The elevation of the front edge of the landslide is $660 \mathrm{~m}$, the elevation of the back edge is $827 \mathrm{~m}$, the height difference is about $207 \mathrm{~m}$, and the volume of the landslide accumulation is 6 million cubic meters. The main sliding direction of the landslide is about $5^{\circ}$ and the length of the main sliding direction is about $1000 \mathrm{~m}$. The boundary of the landslide is basically clear. The boundary of both sides of the landslide is gully. The bedrock in the gully is exposed. The occurrence of the bedrock surface is $5^{\circ}$, which is less than $17^{\circ}$ as shown in Figure 2. The landslide body slides along the bedrock surface. The shape of the landslide accumulation body is as follows: the back edge of the accumulation body is steep, the slope in the middle part is gentle, and the slope at the shear outlet of the front edge is steep, which has typical landslide characteristics.

The reservoir bank slope is subjected to the water-level fluctuations at different rates. Figure 3 shows the schematic of a typical vertical cross section of a $H_{12}$ landslide deposit which is obtained based on the basic geological survey and 1 : 10000 topographic map. The typical sections are intercepted reasonably. The orientation of the sections is consistent with the main sliding direction. The strata are divided into three layers. From top to bottom, the landslide deposits (gravelbearing silty clay), the sliding zones are mainly strong weathered argillaceous sandstone and the magenta siltyargillaceous siltstone.

There is a horizontal displacement of the side walls and the vertical and horizontal ones. Regarding the boundary conditions, horizontal constraints are imposed on both sides of the model, and all nodes on the ground are added with horizontal and vertical constraints. There is water pressure on the slope, and the pressure value is determined by the reservoir water-level. According to the material composition of the landslide and the mechanical parameters of the adjacent rock and soil, the comprehensive calculation determines the calculation parameters as shown in Table 1.

The normal storage water-level is $812 \mathrm{~m}$ and the initial water-level is $625 \mathrm{~m}$, which is lower than the toe of the landslide mass, i.e., the elevation of the landslide body. When the initial water-level is achieved, the river bed in the section is free of water. The reservoir is impounded in three stages: the first stage from the current water-level to $672.5 \mathrm{~m}$, the second stage from $672.5 \mathrm{~m}$ to the dead water-level of $765 \mathrm{~m}$, and the third stage from the dead water-level of $765 \mathrm{~m}$ to the normal water-level of $812 \mathrm{~m}$. The cases modelled in the analysis of the landslide are shown in Table 2.

2.2. Computation Conditions. The finite element model is implemented using the SIGMA/W module of the commercial finite element software GeoStudio. This module is able to correctly model the stability behavior of an unsaturated slope which involves the coupling of seepage and stress-strain behavior of soil. The study that the slope stability analysis under unsaturated soil is calculated using the linear elasticity model implemented in GeoStudio 2007 is proposed by Oh et al. [21].

The soil and the bed rock of the landslide are modelled using an elastoplastic constitutive model and linear elastic constitutive model, respectively. Figure 4 shows the meshes of the landslide soil and bedrock domains. Based on the working conditions of Nuozhadu Reservoir in the periods of impoundment and operation, two scenarios are considered in this study. The parameters used in the analysis are displayed in Table 1.

2.3. Determination of Calculation Method. The fluid-soil interaction is explicitly considered as the finite element modelling. The soil is assumed to be a continuous medium. 


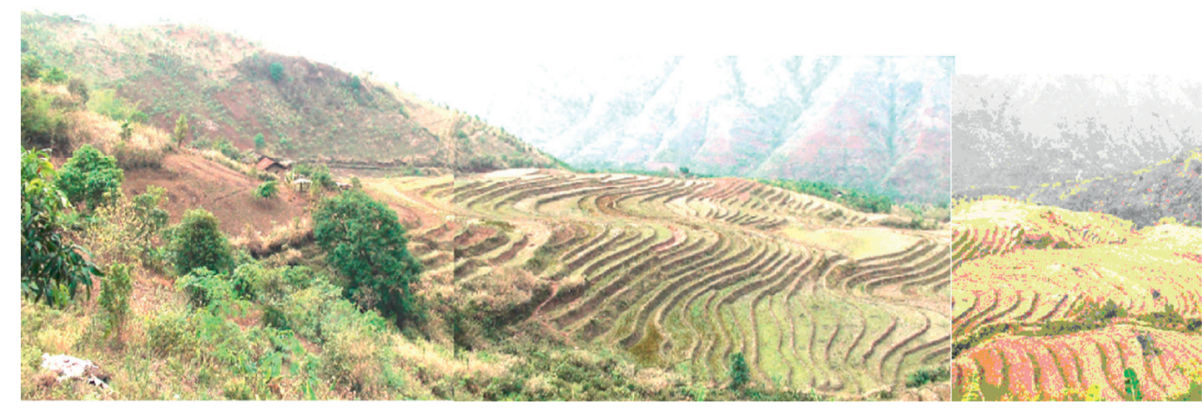

FIgURE 1: Overall picture of the landslide accumulation body.

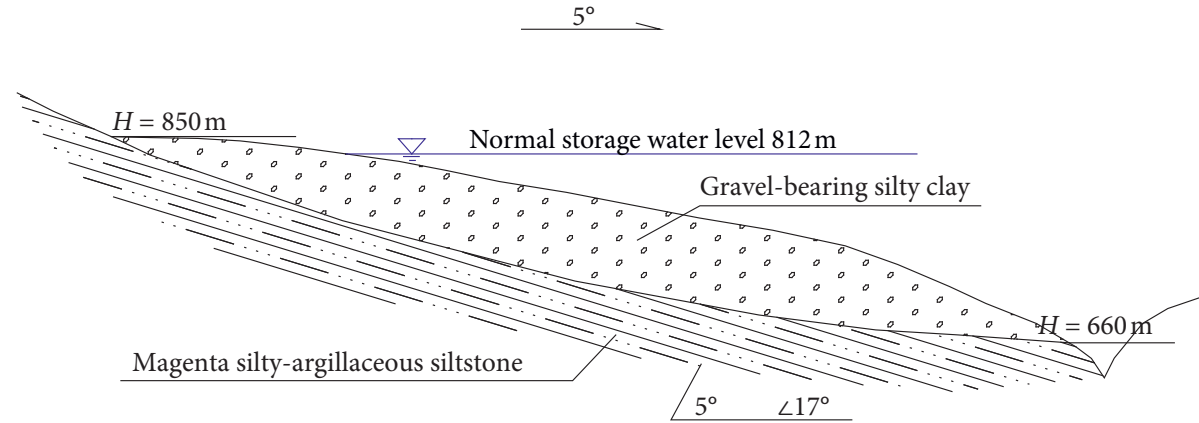

FIGURE 2: Schematic sketch of section $H_{12}$.

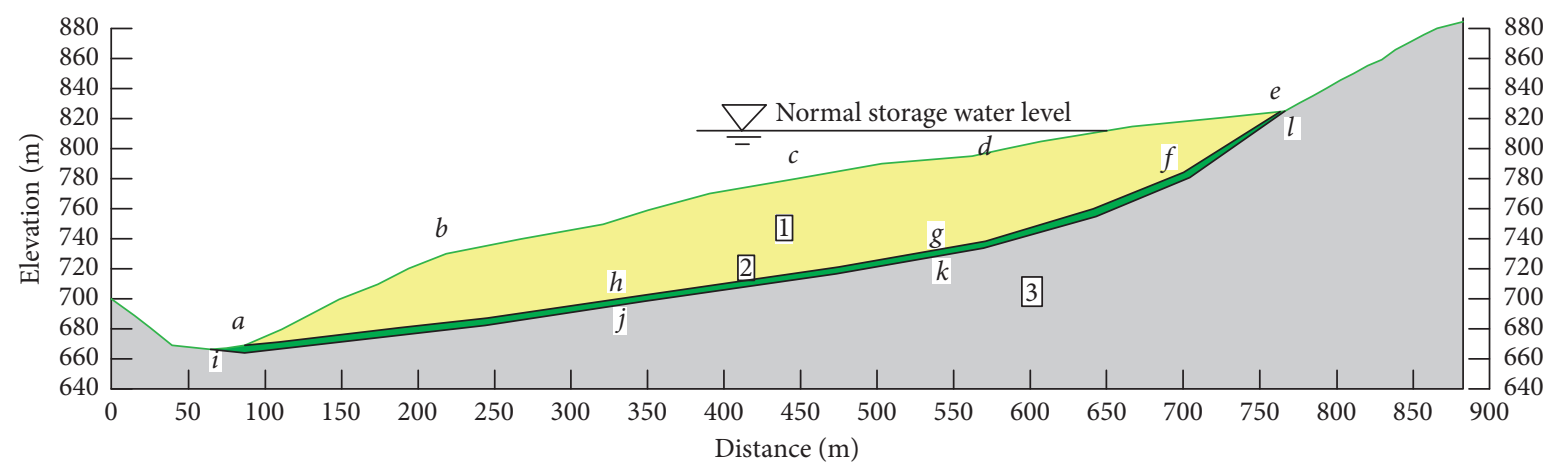

Figure 3: Schematic of a typical vertical cross section of landslide. Notes: Zone 1 (yellow part) is an accumulative body with an average thickness of $40 \mathrm{~m}$; Zone 2 (narrow green part) is a slip zone with highly weathered argillaceous sandstone and an average thickness of about $3 \mathrm{~m}$.

TABLE 1: Mechanical parameters of landslide accumulation and slide zone.

\begin{tabular}{|c|c|c|c|c|}
\hline \multirow{2}{*}{ Parameter } & \multirow{2}{*}{ Symbol } & \multicolumn{2}{|l|}{ Value } & \multirow{2}{*}{ Unit } \\
\hline & & Landslide accumulation zone & Slip zone & \\
\hline Cohesion of saturated soil & $c$ & 16.5 & 15 & $\mathrm{kPa}$ \\
\hline Internal friction angle of saturated soil & $\varphi^{\prime}$ & 20 & 18 & Degree \\
\hline Internal friction angle caused by matrix suction & $\varphi^{b}$ & 16 & 16 & Degree \\
\hline Unit weight & $\gamma$ & 15.8 & 16 & $\mathrm{kN} / \mathrm{m}^{3}$ \\
\hline Saturated unit weight & $\gamma_{\text {sat }}$ & 22 & 22 & $\mathrm{kN} / \mathrm{m}^{3}$ \\
\hline Modulus of elasticity & $E$ & 17 & 15 & $\mathrm{MPa}$ \\
\hline Poisson's ratio & $\mu$ & 0.25 & 0.3 & - \\
\hline
\end{tabular}

The seepage is characterized by the static pore pressure and the hydrodynamic force, which is manifested by the osmotic pressure $P$ applied to a certain action surface and the seepage volume force $f$ distributed in the seepage region. The former is the surface force, and the latter is physical strength; the expression is illustrated in 
TABle 2: Cases modelled in the analysis of landslide.

\begin{tabular}{lcc}
\hline Case no. & Conditions & Research contents \\
\hline Case 1 & Water-level drops from $812 \mathrm{~m}$ to $765 \mathrm{~m}(2 \mathrm{~m} /$ day $)$ & Stability \\
Case 2 & Water-level increases from $672.5 \mathrm{~m}$ to $765 \mathrm{~m}(2 \mathrm{~m} /$ day $)$ & Stability \\
Case 3 & Water-level drops dramatically from $812 \mathrm{~m}$ to $765 \mathrm{~m}(2 \mathrm{~m} /$ day $)$ & Hydromechanical behavior \\
Case 4 & Water-level raises sharply from $672.5 \mathrm{~m}$ to $765 \mathrm{~m}(2 \mathrm{~m} /$ day $)$ & Hydromechanical behavior \\
\hline
\end{tabular}

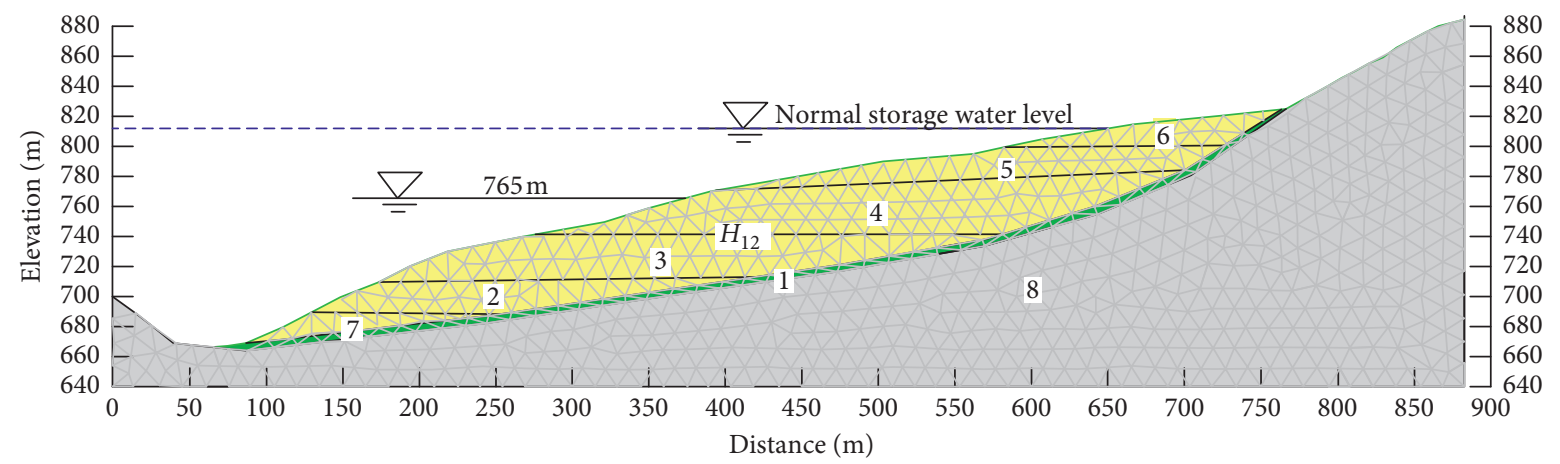

Figure 4: Meshing of finite element model.

$$
\left\{\begin{array}{l}
P=\gamma(H-z), \\
f=\gamma J_{f} .
\end{array}\right.
$$

On the other hand, the permeability coefficient $k$ will change with the volumetric strain $\varepsilon_{v}$ and porosity $n$, which in turn affects the seepage field. The expressions are given by

$$
\left\{\begin{array}{l}
k=k(n), \\
n=n\left(\varepsilon_{v}\right), \\
\varepsilon_{v}=\varepsilon_{v}\left(\sigma_{i j}\right) .
\end{array}\right.
$$

The coupled fluid-soil interaction is implemented using nonlinear finite element method for slope stability analysis. The main steps include solving the seepage field through the initial permeability coefficient $k_{0}$, and obtaining the head distribution so that the hydrostatic pressure and the permeation volume force can be calculated. The above results are then brought into the stress field, and the boundary conditions are combined to resolve the stress field. The volume strain is obtained, and the volume strain is substituted into (2) to solve the permeability coefficient $k_{1}$. The above steps are repeated continuously until equilibrium is arrived to obtain the stress-strain distribution.

\section{Results and Analysis}

3.1. Cases 1 to 2 . When analyzing the stability of the slope due to the sudden rise and fall of the water-level, consider the coupling effect of the seepage force and the stress field; that is, the seepage force is added to the landslide micro-unit, and the variation rate of $2 \mathrm{~m} /$ day is selected and analyzed. As shown in Figure 5, the reservoir water-level is reduced from $812 \mathrm{~m}$ to $765 \mathrm{~m}$. Considering the finite element method stability calculation results of the unsaturated landslide deposits after the coupling of the seepage field and the stress field, the results show the overall sliding. The stability factor is 1.123 , which is generally stable.

When the reservoir water-level rises from $672.5 \mathrm{~m}$ to $765 \mathrm{~m}$, the hydromechanical coupling effect is examined. During the analysis, the matric suction is reckoned. As shown in Figure 6, the factor of safety of the slope is 1.255.

In order to study the influence of the matric suction of unsaturated soil on the stability of unsaturated landslide deposits, the suction force is not considered; that is, the strength of the soil due to suction is removed in the software, and other parameters are unchanged, considering the effect of seepage force. The potential sliding conditions are shown in Figure 7. The factor of safety decreases from 1.255 to 1.138 , which indicates that the matric suction has a positive effect on the slope stability when the water-level rises rapidly.

Compared with the rising condition of the reservoir water-level, the stability of the deposit body is superior to that of the sudden drop. The favorable factors for the antisliding of the reservoir water-level rising are schematically shown in Figure 8. Firstly, the reservoir water-level is suddenly raised, and the landslide body is subjected to the seepage force $F(K)$ addressed to the slope, which is beneficial to enhance the antisliding force. Secondly, during the abrupt rise of the water-level, the water will be pressed by a selfweight in a short period of time, which is perpendicular to the slope $F^{\prime}(N)$. The slope foot increases the antislip force of the leading edge, which increases the stability of the entire slope. The unfavorable factors of water storage on slope stability also exist. After a period of water storage, the front edge of the slope is saturated, and the leading edge rock and soil itself will decrease due to water immersion strength, reducing the resistance. The sliding force causes a landslide. Because the leading edge of the slope is saturated by the upward pressure $F(N)$ of the water after the leading edge is saturated, the water seeps into the sliding surface to play a lubricating role, so that the anterior edge antisliding force 


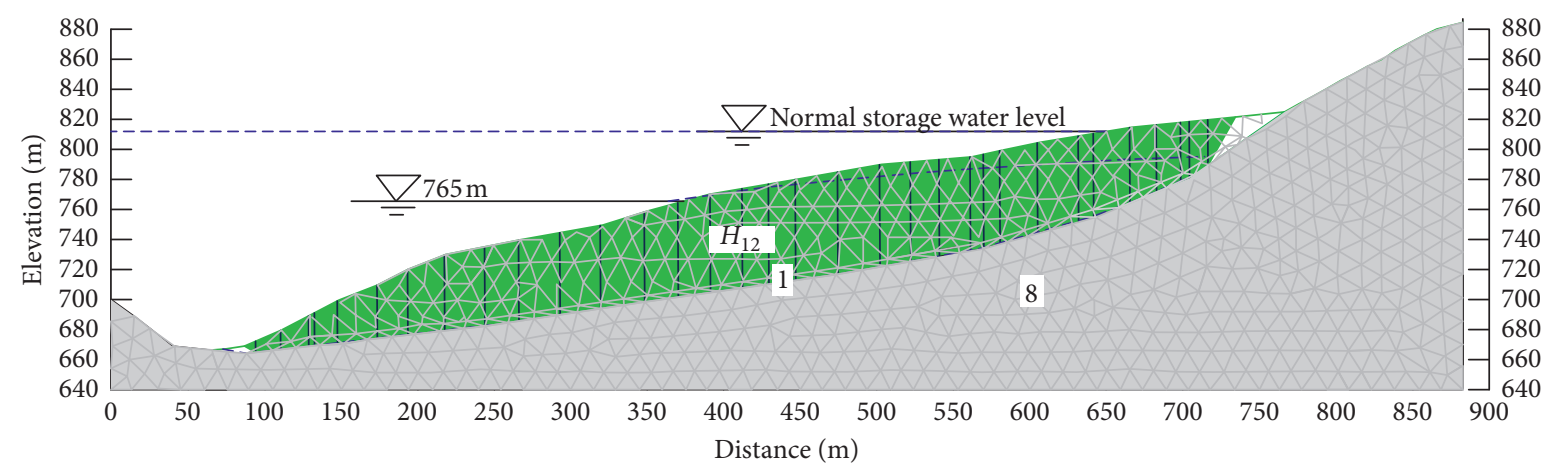

Figure 5: Potential sliding zone (green part) of Case 1 with water-level dropping from $812 \mathrm{~m}$ to $765 \mathrm{~m}$ at a rate of $2 \mathrm{~m} / \mathrm{day}\left(F_{\mathrm{S}}=1.123\right)$.

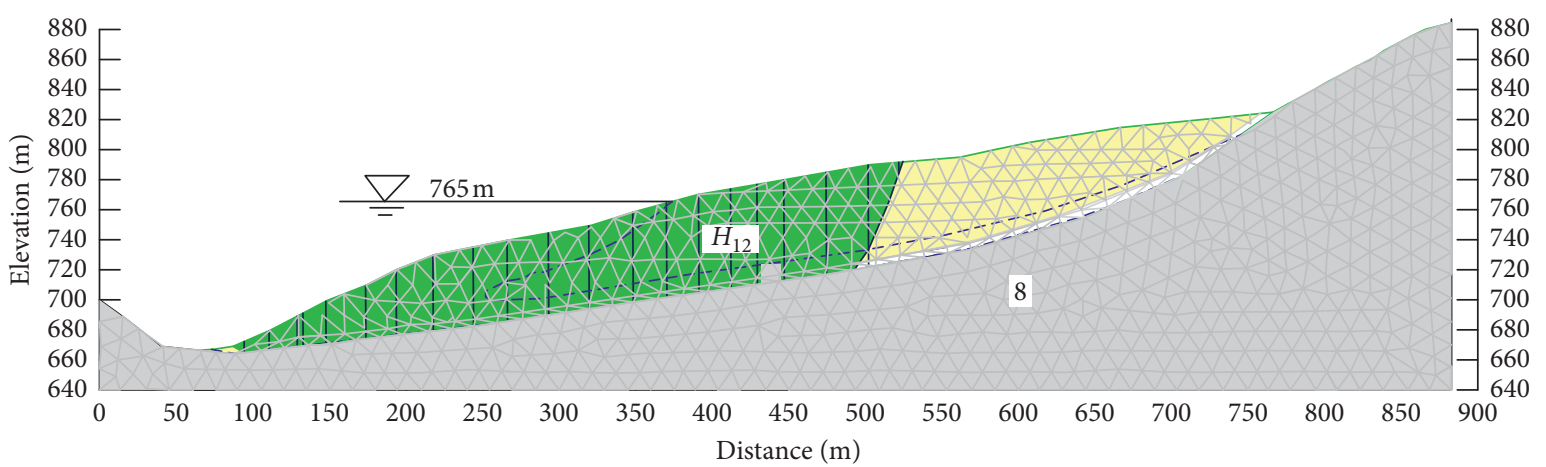

Figure 6: Potential sliding zone (green part) of Case 2 with water-level increases from $672.5 \mathrm{~m}$ to $765 \mathrm{~m}$ at a rate of $2 \mathrm{~m} / \mathrm{day}$, considering the hydromechanical coupling effect, and the suction force is considered $\left(F_{\mathrm{S}}=1.255\right)$.

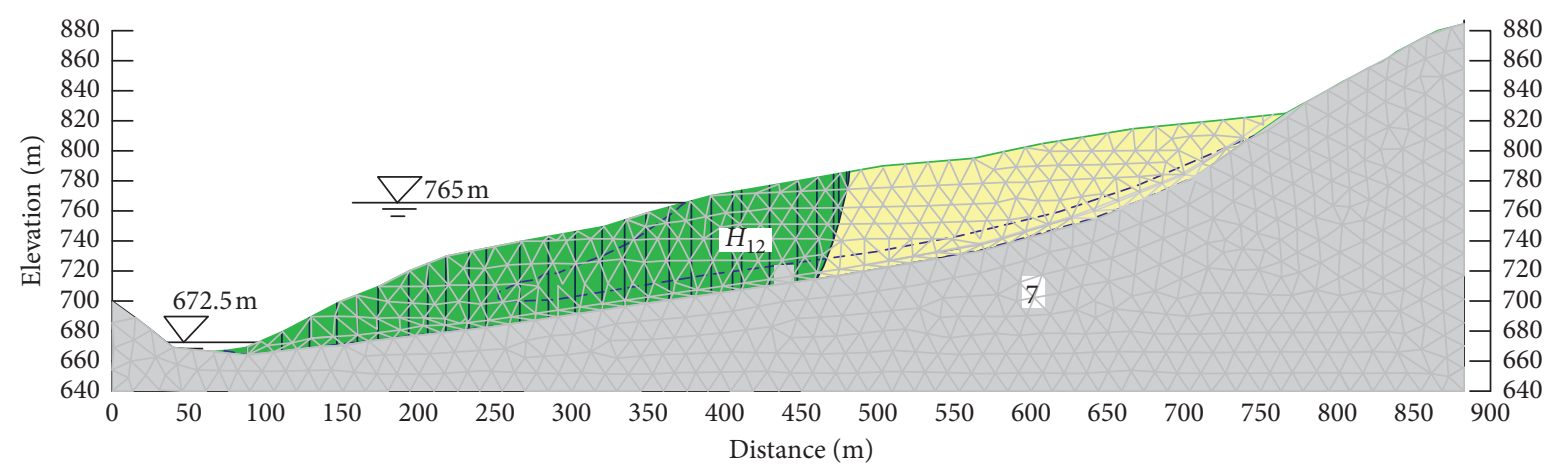

Figure 7: Potential sliding zone (green part) of Case 2 with water-level increases from $672.5 \mathrm{~m}$ to $765 \mathrm{~m}$ at a rate of $2 \mathrm{~m} / \mathrm{day}$, considering the hydromechanical coupling effect.

reduces. However, under the condition of water-level dropping at a rate of $2 \mathrm{~m} /$ day, the stability coefficient of the slope is broad and safe, indicating that the favorable factors are greater than the unfavorable factors.

The slope stability under the influence of the matrix suction in the unsaturated zone is also considered. It is found that when the matrix suction is calculated, the stability of the slope is likely to be improved, and the increase is mainly dominated by the range of the unsaturated zone. The larger the range, the greater the increase in stability. Under the condition of the reservoir water-level falling, the range of the unsaturated zone is not as large as that of the rising condition, so the unsaturated zone has less impact on the stability of the slope under the precipitation condition. The above results suggest that the landslide accumulation body is stable under all the above-mentioned reservoir water-level fluctuation conditions. The calculation results are more accurate when the hydromechanical coupling effect is reckoned under unsaturated conditions.

3.2. Case 3. Figure 9 shows the seepage velocity field in landslide deposit $H_{12}$ for Case 3 with water-level dropping from $812 \mathrm{~m}$ to $765 \mathrm{~m}$ at a rate of $2 \mathrm{~m} /$ day. As can be seen, the maximum seepage velocity occurs near the slope surface at water elevation of $765 \mathrm{~m}$, i.e., a velocity of $2 \mathrm{~m} /$ day, which is 


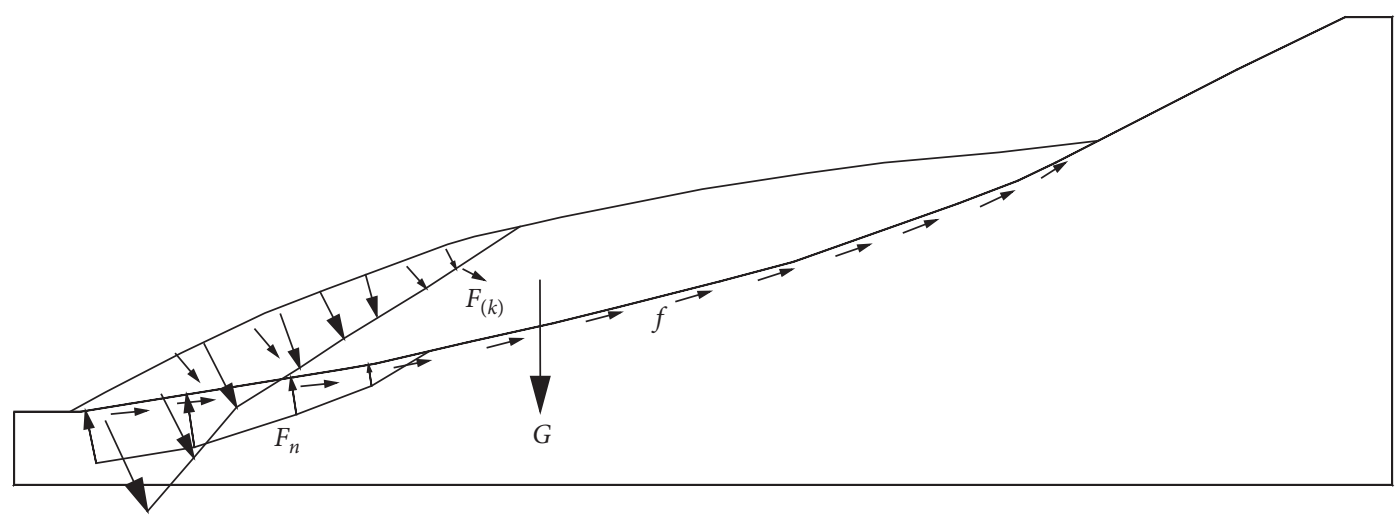

FIgURE 8: Schematic diagram of the force of the landslide body when the water-level rises suddenly.

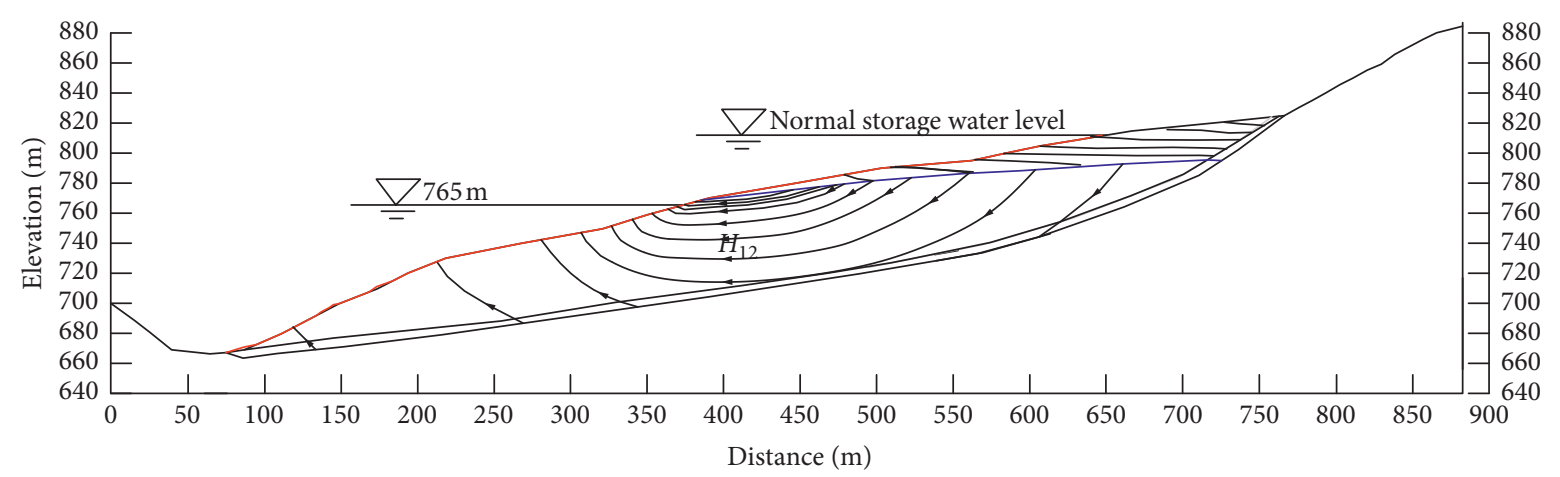

FIgURE 9: Seepage velocity field in landslide deposit $H_{12}$ for Case 3 with water-level dropping from $812 \mathrm{~m}$ to $765 \mathrm{~m}$ at a rate of $2 \mathrm{~m} / \mathrm{day}$.

probably due to the relatively low soil permeability coefficient. The seepage velocity is a key influence factor on the stability of slopes [22]. This can be reflected from pore water pressure and saturation change. This effect would become more significant when the direction of flow velocity is the same as the sliding direction and the flow velocity is greater than the sliding velocity of the landslide.

Figure 10 shows the contours of the displacement, shear stress, and strain of the landslide for Case 3 with water-level dropping from $812 \mathrm{~m}$ to $765 \mathrm{~m}$ at a rate of $2 \mathrm{~m} /$ day. The displacement, shear stress, and strain distribution calculated by considering the coupling effect of the seepage field and the stress field are displayed in the displacement contour map along the horizontal and vertical directions. There is $\mathrm{x}$-zero displacement at the $475 \mathrm{~m}$ of the landslide body. Due to the water pressure acting on the slope after water storage, the soil is consolidated and displaced along the positive direction of $x$-axis. The maximum displacement value is $0.31 \mathrm{~m}$ at $x$-axis of $200 \mathrm{~m}$. At the trailing edge of the landslide body, due to the combined action of the sliding force and the seepage force, the trailing edge has a displacement along the negative $x$-axis direction, and the maximum value of $0.29 \mathrm{~m}$ is located at the trailing edge of the landslide. The displacement along $y$-axis is predominantly negative. The maximum settlement is $0.78 \mathrm{~m}$, which is mainly due to soil consolidation caused by water pressure. The above results indicate that the potential failure mode is a typical thrust load-caused landslide.
The consequences of stress-strain calculation show that the shear stress is concentrated in the linear elastic model of the sliding bed; the maximum value reaches $2500 \mathrm{kPa}$. The landslide body is elastoplastic model, the shear stress is small, but the shear strain is large, and the shear strain at the landslide front and slip surface is great.

3.3. Case 4. Figure 11 shows the displacement, shear stress, and shear strain contours when the reservoir water-level rises from $672.5 \mathrm{~m}$ to $765 \mathrm{~m}$ at a rate of $2 \mathrm{~m}$ /day. From the dip displacement and stress-strain distribution contours, the following findings can be observed. Firstly, when the reservoir water-level rises, the displacement of the landslide body is lower than the reservoir water-level from $812 \mathrm{~m}$ to $765 \mathrm{~m}$. The shear strain is much smaller. Because the reservoir water-level rises sharply, the projection of the seepage force direction and the sliding direction is negative, which offsets the effect of a part of the sliding force. Therefore, when the water-level rises, the displacement of the landslide body tends to be small. Secondly, at the elevation of $765 \mathrm{~m}$, the seepage force exists along the opposite direction of the sliding direction, and the trailing edge receives the glide force caused by gravity; as a result, two zero displacement lines appear in the sliding body along $x$-axis displacement contour. In the shear strain contour map, two zero shear strain lines also appear in the sliding body. Thirdly, the shear stress distribution in the sliding body is the same as that 


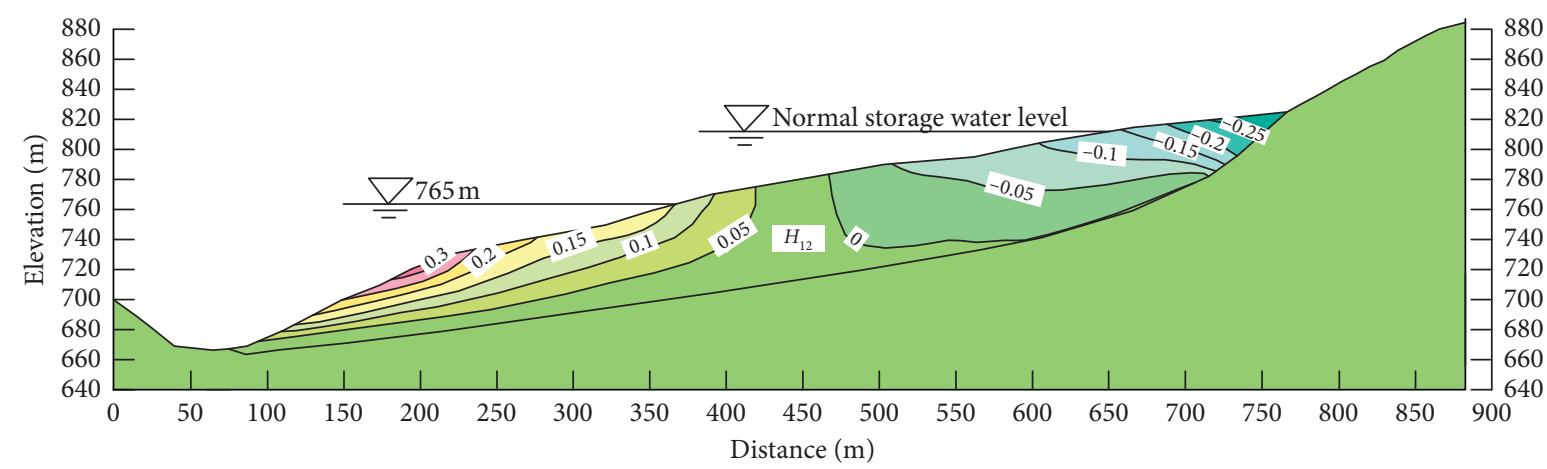

(a)

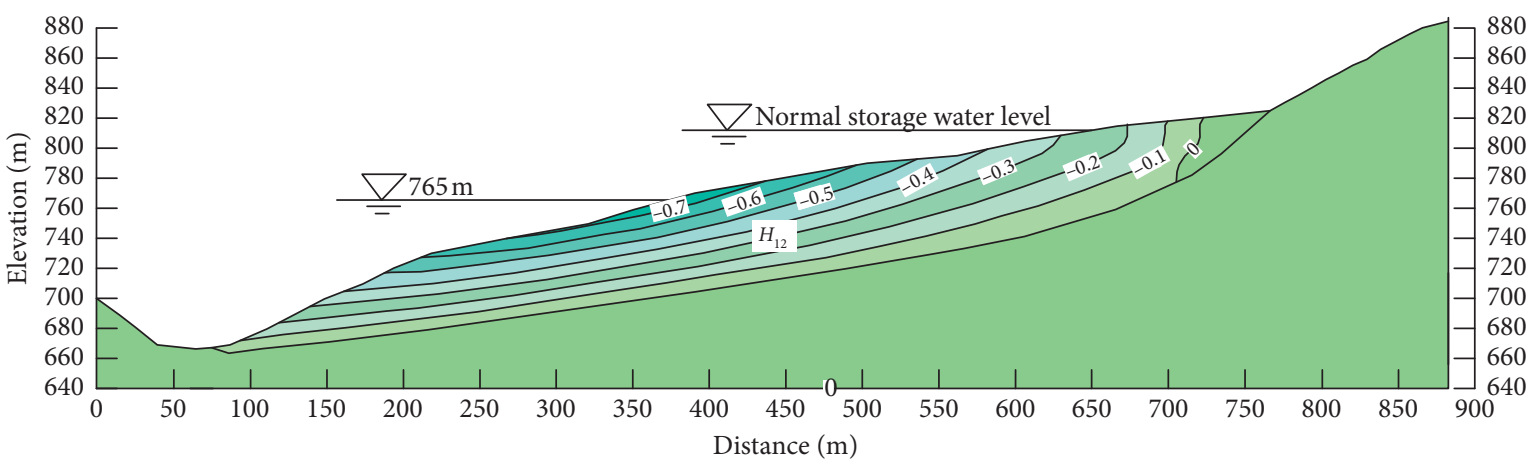

(b)

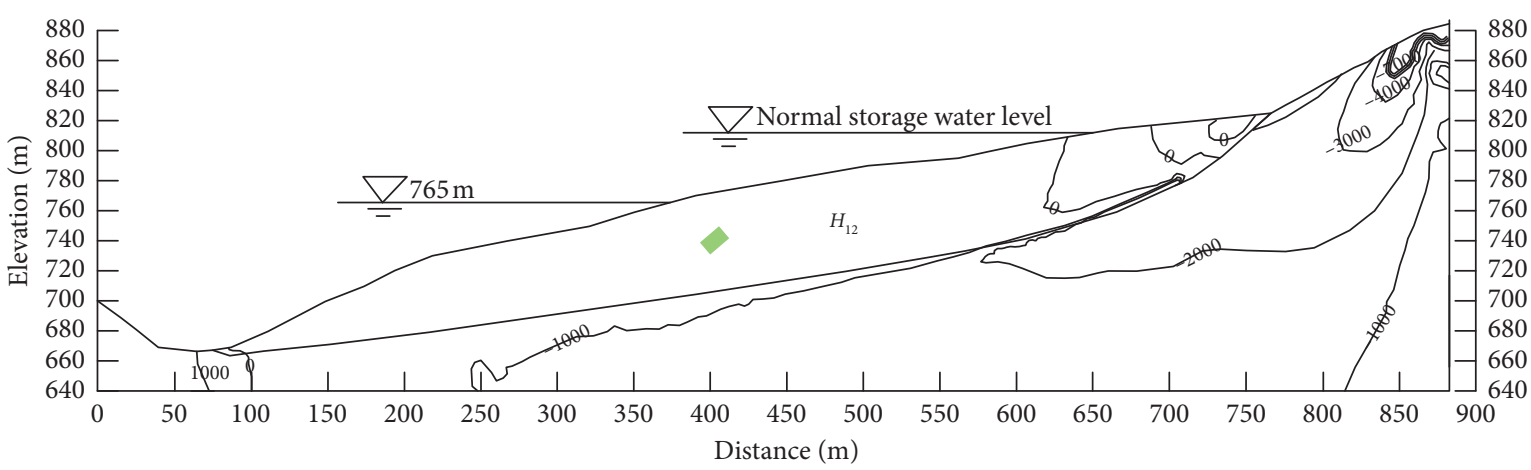

(c)

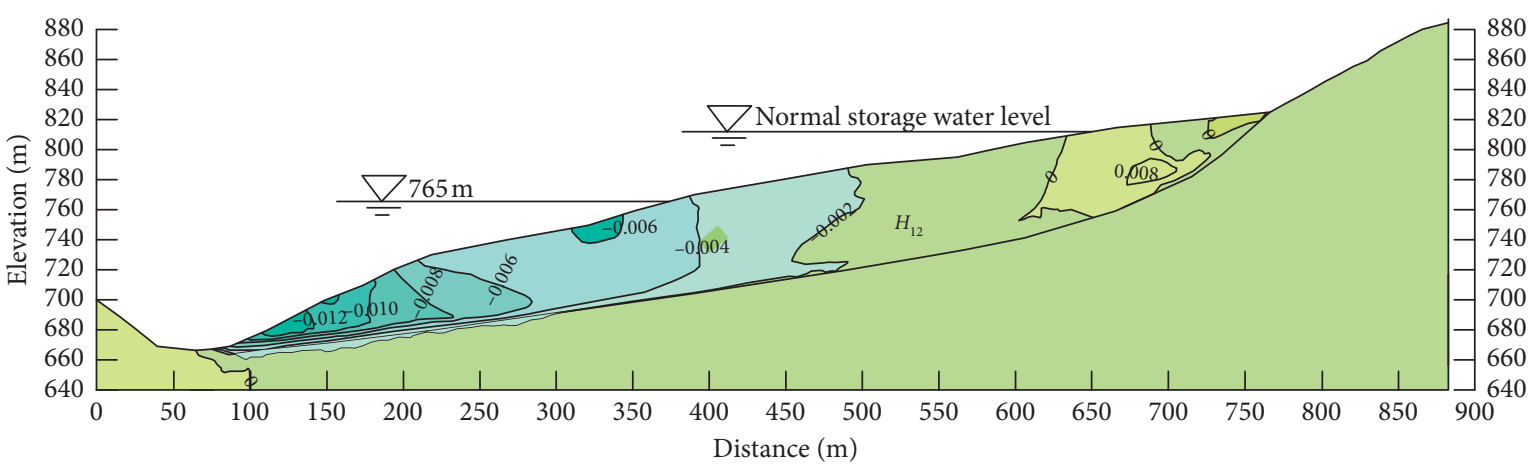

(d)

Figure 10: Soil behavior for Case 3 with water-level dropping from $812 \mathrm{~m}$ to $765 \mathrm{~m}$ at a rate of $2 \mathrm{~m} /$ day. (a) Horizontal displacement contour (unit: m). (b) Vertical displacement contour (unit: m). (c) Shear stress contour (unit: $\mathrm{kPa}$ ). (d) Shear strain contour. 


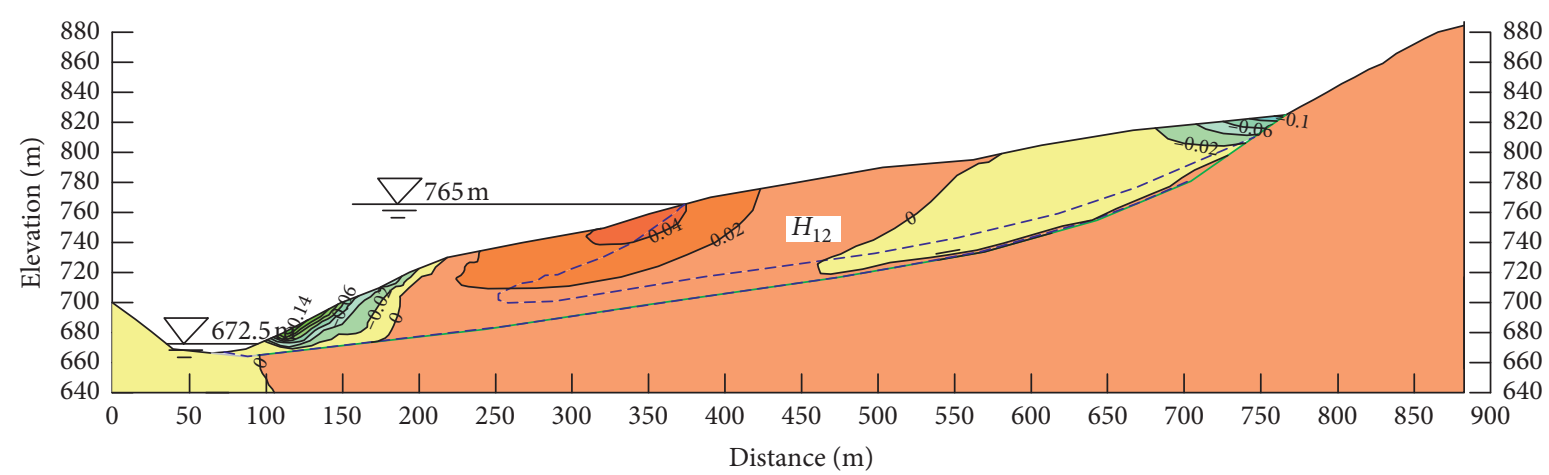

(a)

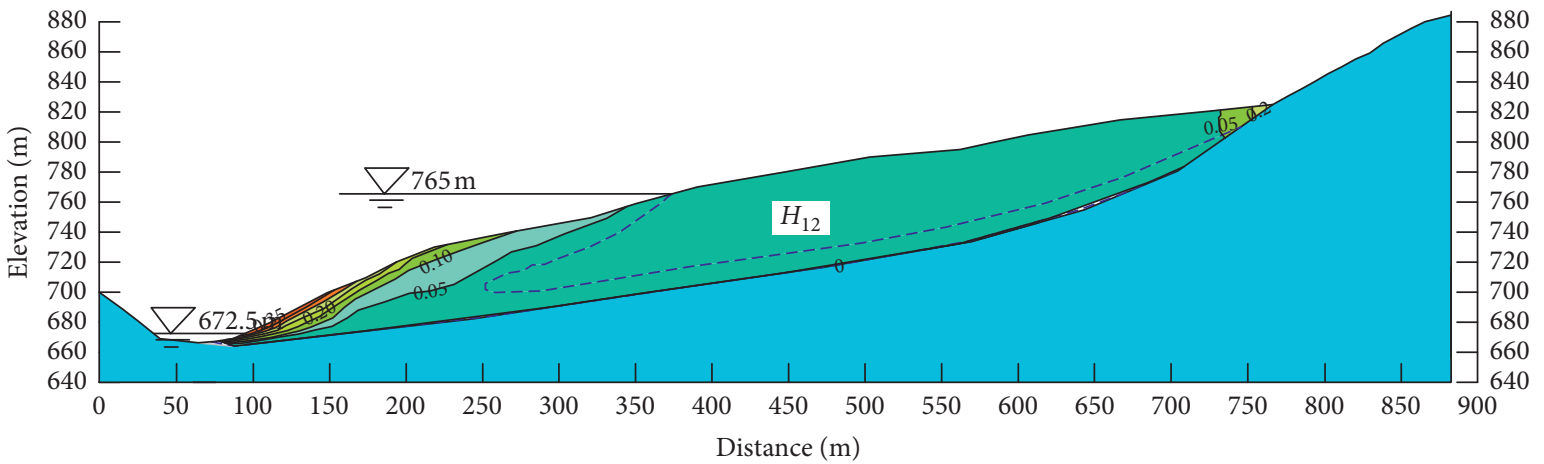

(b)

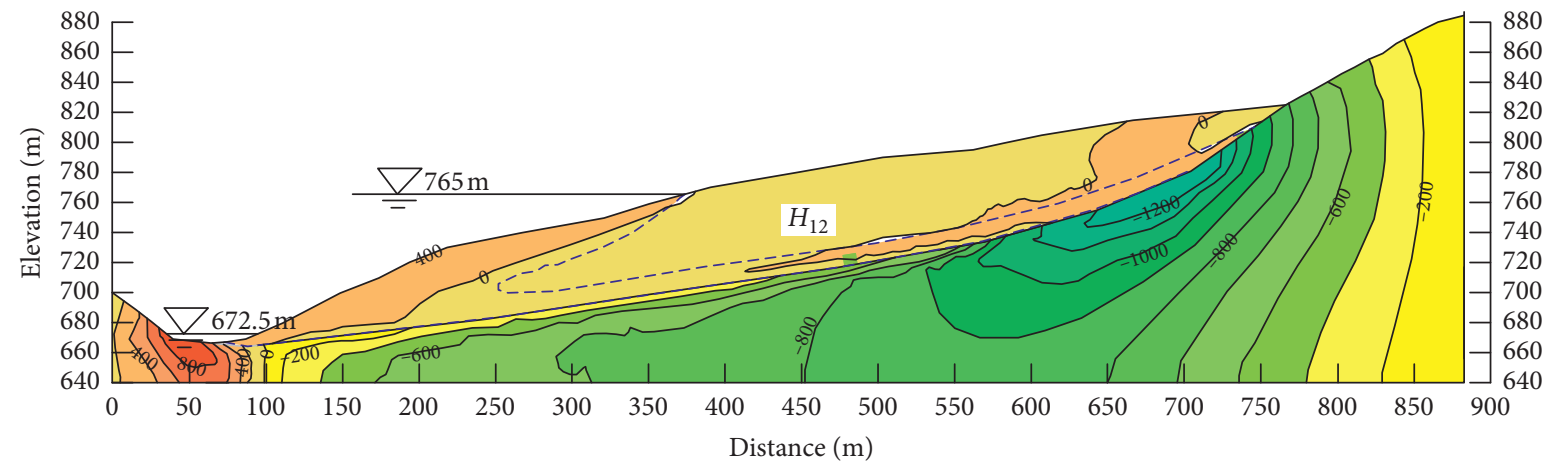

(c)

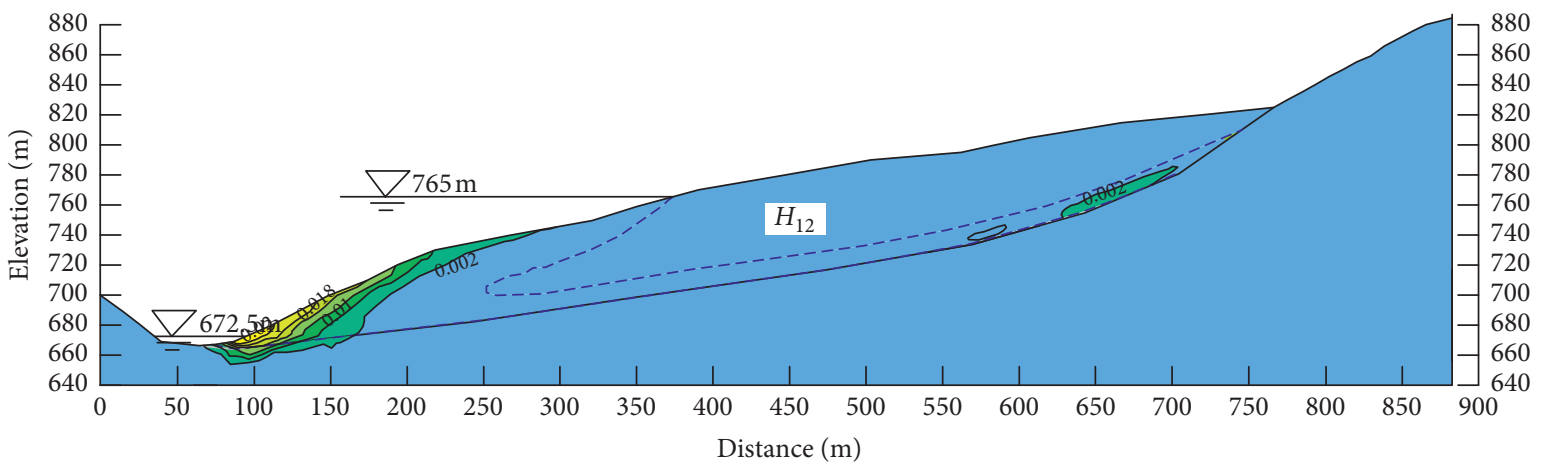

(d)

FiguRE 11: Soil behavior for Case 4 with water-level rising from $672.5 \mathrm{~m}$ to $765 \mathrm{~m}$ at a rate of $2 \mathrm{~m} /$ day. (a) Horizontal displacement contour (unit: m). (b) Vertical displacement contour (unit: m). (c) Shear stress contour (unit: $\mathrm{kPa}$ ). (d) Shear strain contour. 
under the precipitous drop condition, and the shear stress is large in the sliding bed. The shear strain distribution is great in the sliding body and small in the sliding bed.

\section{Conclusions}

Based on the study of rapid water-level fluctuations on the stability and hydromechanical behavior of an unsaturated reservoir bank slope, the following conclusions can be obtained.

(1) The matrix suction should be considered when calculating the stability of unsaturated soil, which is beneficial for slope stability in unsaturated soil.

(2) The stability of an unsaturated reservoir bank is weaker when the water-level drops dramatically and then rises sharply. The result is attributed to the orientation of seepage force being inclined to the outer edge of the slope when the water-level drops dramatically.

(3) The coupled seepage-soil stress field should be considered in calculating the stability of an unsaturated reservoir bank slope when the water-level changes rapidly.

(4) The unsaturated area of the slope body is becoming smaller after the water-level rises abruptly, which can make the reservoir bank slope be unstable.

In the process of water storage, due to the rapid disappearance of the matrix suction, it is not difficult to cause some shallow surface landslides. It is found that the most dangerous working condition for the bank slope is under deliberate storage and quick release of water. Compared with the rising condition of the reservoir water-level, the deposit body is more stable than that of the sudden water-level drop condition. When the matrix suction is reckoned, the stability of the slope is likely to be improved. A larger unsaturated zone often benefits the slope stability. This study is based on 2D model, and a more complete assessment should consider a 3D model of slope. As a multiphase material, the soil along the sliding surface should be spatially variable (see $[23,24]$ ) which may also affect the failure mode and sliding velocity. These form strands of future work.

\section{Data Availability}

The data used to support the findings of this study are available from the corresponding author upon request.

\section{Conflicts of Interest}

The authors declare that they have no conflicts of interest.

\section{Acknowledgments}

This research was supported by the National Key Research and Development Program of China (Grant no. 2018YFC1505006) and the National Natural Science Foundation of China (Grant no. 51879203).

\section{References}

[1] N. Liu, Z. Chen, J. Zhang, W. Lin, W. Chen, and W. Xu, "Draining the Tangjiashan barrier lake," Journal of Hydraulic Engineering, vol. 136, no. 11, pp. 914-923, 2010.

[2] Y. Yin, B. Huang, W. Wang et al., "Reservoir-induced landslides and risk control in three gorges project on Yangtze river, China," Journal of Rock Mechanics and Geotechnical Engineering, vol. 8, no. 5, pp. 577-595, 2016.

[3] K.-Q. Li, D.-Q. Li, P.-T. Li, and Y. Liu, "Meso-mechanical investigations on the overall elastic properties of multi-phase construction materials using finite element method," Construction and Building Materials, vol. 228, p. 116727, 2019.

[4] C. W. W. Ng, L. T. Zhan, C. G. Bao, D. G. Fredlund, and B. W. Gong, "Performance of an unsaturated expansive soil slope subjected to artificial rainfall infiltration," Géotechnique, vol. 53, no. 2, pp. 143-157, 2003.

[5] Y. Tang, W. Wu, K. Yin, S. Wang, and G. Lei, "A hydromechanical coupled analysis of rainfall induced landslide using a hypoplastic constitutive model," Computers and Geotechnics, vol. 112, pp. 284-292, 2019.

[6] D. G. Fredlund, Two-Dimensional Finite Element Program Using Constant Strain Triangles, University of Saskatchewan Transportation and Geotech, Saskatoon, Canada, 1978.

[7] D. G. Fredlund, J. Krahn, and D. E. Pufahl, "The relationship between limit equilibrium slope stability methods," Proceedings of the International Conference on Soil Mechanics and Foundation Engineering, vol. 3, pp. 409-416, 1981.

[8] S. Qi and S. K. Vanapalli, "Influence of swelling behavior on the stability of an infinite unsaturated expansive soil slope," Computers and Geotechnics, vol. 76, pp. 154-169, 2016.

[9] Y. Liu, H. Xiao, K. Yao, J. Hu, and H. Wei, "Rock-soil slope stability analysis by two-phase random media and finite elements," Geoscience Frontiers, vol. 9, no. 6, pp. 1649-1655, 2018.

[10] Y. Liu, W. Zhang, L. Zhang, Z. Zhu, J. Hu, and H. Wei, "Probabilistic stability analyses of undrained slopes by 3D random fields and finite element methods," Geoscience Frontiers, vol. 9, no. 6, pp. 1657-1664, 2018.

[11] N. Hiroyuki, "Discussions on reservoir landslide," Bulletin of Soil and Water Conservation, vol. 10, no. 1, pp. 53-64, 1990.

[12] D. G. Fredlund and H. Rahardjo, Soil Mechanics for Unsaturated Soils, Wiley, Hoboken, NJ, USA, 1993.

[13] D. G. Fredlund, A. Xing, M. D. Fredlund, and S. L. Barbour, "The relationship of the unsaturated soil shear strength to the soil-water characteristic curve," Canadian Geotechnical Journal, vol. 33, no. 3, pp. 440-448, 1996.

[14] W. J. Zhang, L. T. Zhan, D. S. Ling, and Y. M. Chen, "Influence of reservoir water level fluctuations on stability of unsaturated soil banks," Journal of Zhejiang University (Engineering Edition), vol. 40, no. 8, pp. 1365-1370, 2006.

[15] X. H. Luo and H. Y. Ye, "Stability analysis of soil slope considering matric suction," Rock and Soil Mechanics, vol. 28, no. 9, pp. 1919-1922, 2007, in Chinese.

[16] L. Zhang, F. Wu, Y. Zheng, L. Chen, J. Zhang, and X. Li, "Probabilistic calibration of a coupled hydro-mechanical slope stability model with integration of multiple observations," Georisk: Assessment and Management of Risk for Engineered Systems and Geohazards, vol. 12, no. 3, pp. 169182,2018

[17] D. H. Fredlund, D. P. Do, and D. Hoxha, "Effective elastic and hydraulic properties of fractured rock masses with high contrast of permeability: numerical calculation by an embedded fracture continuum approach," Advances in Civil Engineering, vol. 2019, Article ID 7560724, 21 pages, 2019. 
[18] T. M. H. Le, M. Sanchez, D. Gallipoli, and S. Wheeler, "Probabilistic study of rainfall-triggered instabilities in randomly heterogeneous unsaturated finite slopes," Transport in Porous Media, vol. 126, no. 1, pp. 199-222, 2019.

[19] Y. Wheeler, L. Q. He, Y. J. Jiang, M. M. Sun, E. J. Chen, and F.-H. Lee, "Effect of in situ water content variation on the spatial variation of strength of deep cement-mixed clay," Géotechnique, vol. 69, no. 5, pp. 391-405, 2019.

[20] G. Chen, Q.-Y. Li, D.-Q. Li, Z.-Y. Wu, and Y. Liu, "Main frequency band of blast vibration signal based on wavelet packet transform," Applied Mathematical Modelling, vol. 74, pp. 569-585, 2019.

[21] S. Oh and N. Lu, "Slope stability analysis under unsaturated conditions: case studies of rainfall-induced failure of cut slopes," Engineering Geology, vol. 184, pp. 96-103, 2015.

[22] R. L. Michalowski, "Slope stability analysis: a kinematical approach," Géotechnique, vol. 45, no. 2, pp. 283-293, 1995.

[23] L. Li, C. Li, and C. He, "Analysis of mechanical response for a reinforced bedded rock slope under rainfall," Advances in Civil Engineering, vol. 2019, Article ID 9864230, 9 pages, 2019.

[24] K.-Q. Li, D.-Q. Li, and Y. Liu, "Meso-scale investigations on the effective thermal conductivity of multi-phase materials using the finite element method," International Journal of Heat and Mass Transfer, vol. 151, p. 119383, 2020. 